C. Cuadra, et al., Int. J. of Safety and Security Eng., Vol. 6, No. 1 (2016) 40-52

\title{
DYNAMIC CHARACTERISTICS OF A BRIDGE ESTIMATED WITH NEW BOLT-TYPE SENSOR, AMBIENT VIBRATION MEASUREMENTS AND FINITE ELEMENT ANALYSIS
}

\author{
C. CUADRA ${ }^{1}$, N. SHIMOI ${ }^{1} \&$ M. SAIJO ${ }^{2}$ \\ ${ }^{1}$ Faculty of System Science and Technology, Akita Prefectural University, Japan. \\ ${ }^{2} \mathrm{OYO}$ Corporation, Japan.
}

\begin{abstract}
Applicability of new bolt-type piezoelectric bolt sensor to estimate dynamic properties of bridges is verified by comparing measurement results with those obtained from ambient vibration observations and from finite element method of analysis. For this study a bridge located at Yurihonjo city, Japan, was chosen as the target structure. The structure is a multiple-span type bridge with steel beams of variable sections and reinforced concrete slabs to support the asphalt carpet. The bridge consists of seven spans with a total length of $256 \mathrm{~m}$. The experimental measurements using the new bolt-type sensor were performed only on the first span near the left abutment. However, ambient vibration measurements and analysis were done for all spans. In general, responses were obtained appropriately using the new sensor and that results are comparable with those obtained from analysis and ambient vibration measurements.
\end{abstract}

Keywords: ambient vibration, finite element method, natural frequency of vibration, piezoelectric bolt sensor.

\section{INTRODUCTION}

Estimation of dynamic characteristics of bridge structures is an important task to evaluate their seismic response and to investigate their structural safety. Potential damages can be detected by a periodical of continuing monitoring to prevent collapse of bridges. In Japan, after the Second World War many bridges were constructed as an important part of the reconstruction tasks. Therefore, these bridges present some deterioration due to ageing and due to action of past earthquakes. Moreover, in the decade of 1980 of the last century, constructions of large projects of buildings and bridges were initiated. Then, high demand of materials, in special for reinforced concrete structures, induced to use sea sand, which contains salts that in reaction with water and cement causes corrosion of steel reinforcement. Outside Japan, an example of the necessity of health monitoring was evident in the collapse of the bridge I-35W on Mississippi river in USA. During the evening rush hour on August 1, 2007, the bridge suddenly collapsed, killing 13 people and injuring 145. In case of Japan, the Ministry of Land and Transportation has performed a study on vulnerability of bridges and 121 cases of bridges in danger have been reported [1,2]. The risk is due to deterioration of aged concrete bridges (weathering) and corrosion of steel bridges.

A continuous or real-time structural health monitoring could help to prevent damages. Monitoring systems already exist; however, they are in general designed to be installed in new structures and are expensive. For existing old structures, simple and cheap sensor systems are required. In this research, a new sensor that is based on piezoelectric cable [3-6] inserted into a bolt shape is developed and its applicability to perform health monitoring of structures is verified by means of a series of measurements on vibration of a target bridge.

To implement a monitoring system and to verify its reliability first, a basic estimation of dynamic characteristics of a target bridge was performed [7-9]. The Asuka Ohashi Bridge 
which is located at Yurihonjo city in Japan was selected as the target structure. The structure is a multiple-span type bridge with steel beams of variable sections and reinforced concrete slabs to support the asphalt carpet. The bridge consists of seven spans with a total length of $256 \mathrm{~m}$. Ambient vibration measurements were performed by authors to estimate natural frequencies of vibration in the selected structure. Microvibration sensors were set up at middle of each span, and measurements were performed simultaneously. Since girder sections are not equal for each span and spans at bridge ends have different lengths, predominant frequencies are also different for each span. Using finite element method for analysis, modes of vibration were identified and correlated with peaks of Fourier spectrum obtained from in situ ambient vibration measurements. The main modes of vibrations correspond to vertical vibration of the bridge. Then, these predominant frequencies of vibration are compared with those obtained from measurements using piezoelectric bolt sensors. In this last case, piezoelectric sensors were set up only at one span near left abutment. Moreover, dynamic properties of the selected span were verified using conventional accelerometers $[10,11]$.

\section{TARGET BRIDGE AND AMBIENT VIBRATION MEASUREMENTS}

The investigated bridge was constructed in 1979 and it is part of the Japanese national route number 105. The name of the bridge is Asuka Ohashi (actually, in Japanese Ohashi means large bridge and was designated with this name by comparison with an old bridge near the site which had less length).

The bridge is 256-m length and connects the south and north-east part of Akita prefecture as a part of the route 105. It must be noted that the routes of Japan are numbered according to their year of construction, where lower numbers correspond to oldest routes. Elevation scheme and plan view can be appreciated in Fig. 1. Spans are labeled with encircled numbers from (1) to (7). A general photograph is shown in Fig. 2. The deck is $22.8-\mathrm{m}$ wide and consisted of cast in place reinforced concrete slab supported by longitudinal steel girders. The structure consists of seven spans where spans at both ends have $30.5 \mathrm{~m}$ of nominal length and other central spans have 38-m nominal length. Spans are connected by expansion joints and span can be considered as single-supported structure. Details of girders and a view of road carpet are shown in Fig. 3.

Two series of ambient vibration measurements were carried out, using seven simultaneous recording data loggers with three channels per data logger. That is, 21 channels were measured in total. Sensors were located on the pedestrian deck and distributed as is shown by encircled numbers in Figs 1 and 2. Three components of vibration were measured at each point of observation. All sensors were located on the central portion of each span. Six hundred seconds were measured using a sampling ratio of $100 \mathrm{~Hz}$ to provide good wave-form definition. Figure 4 shows some details of the equipment for micro vibration measurements. First, all equipment is calibrated and chronometers are synchronized using GPS information obtained from satellites. Sensors for two horizontal directions and for vertical direction are set up at each selected point of measurement. Sensor in horizontal directions corresponds to longitudinal and transversal directions of the bridge. Sensor in vertical direction permits to obtain the larger vertical vibration of each span of the bridge. Measurements were performed in a morning with normal traffic condition and therefore vehicles passing the bridge excite the vertical vibration of the bridge. Data loggers were set up to start measurements simultaneously, and data were stored in memory cards for its posterior analysis. Data logger is 


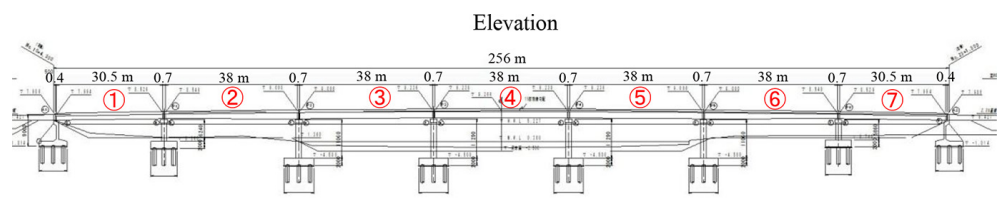

Plan View

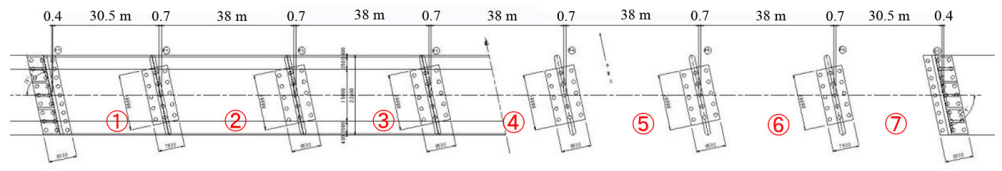

Figure 1: Elevation and plan view schemes of Asuka Ohashi bridge.

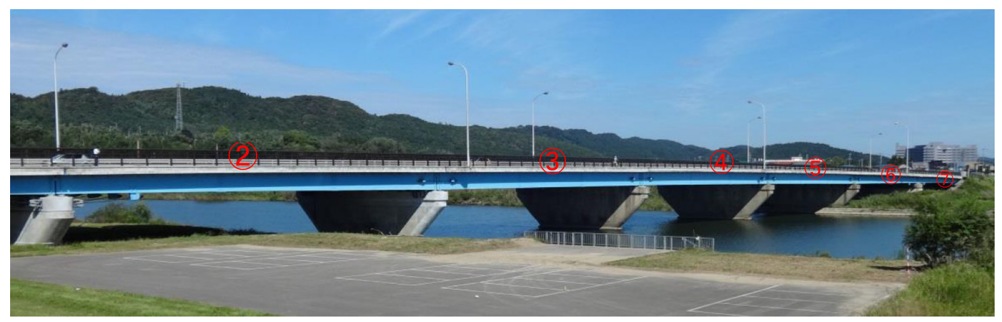

Figure 2: General photograph of Asuka Ohashi bridge.
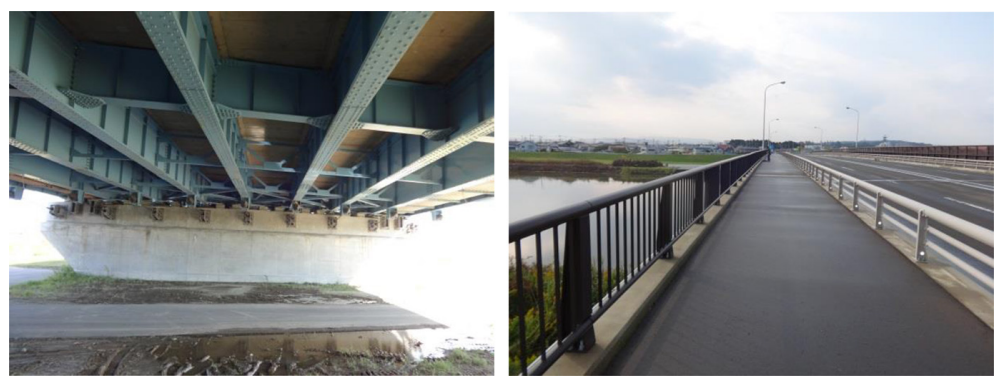

Figure 3: Details of girders and view of bridge deck.

SAMTAC-802C made by Tokyo Sokushin Co. Ltd, and sensors were magnetic-coil type with a range of measurement from 0.2 to $50 \mathrm{~Hz}$.

As was mentioned previously, the largest response of the vibration was observed for the vertical component. It was detected that each span has its own predominant frequency. Spans for points (1)-(6), which are presented in Fig. 1, are of the same length; however, dimensions of steel beams and support condition are different. Spans for points (1) and (7), which are spans near abutments, have same length; however, this length is shorter than the length for other spans. Therefore, to observe the difference between different types of span, responses at points (1)-(4) were chosen and their correspondent Fourier spectrum is shown in Fig. 5. The 


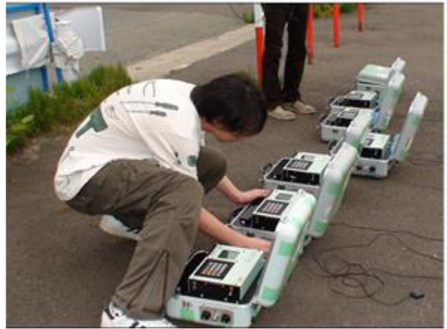

Equipment calibration and synchronization

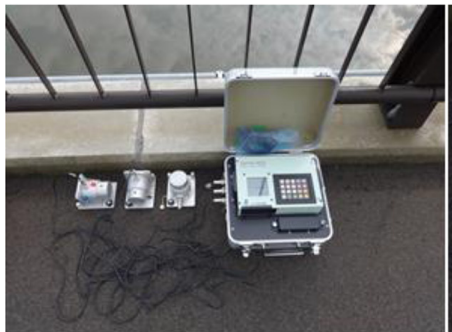

Typical point of measurements

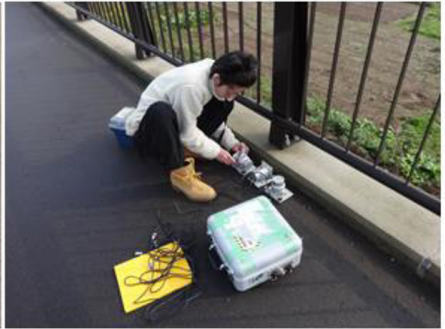

Sensors setup

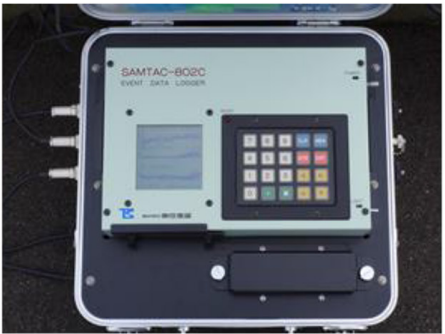

Detail of data logger screen

Figure 4: Details of measurements and equipment.
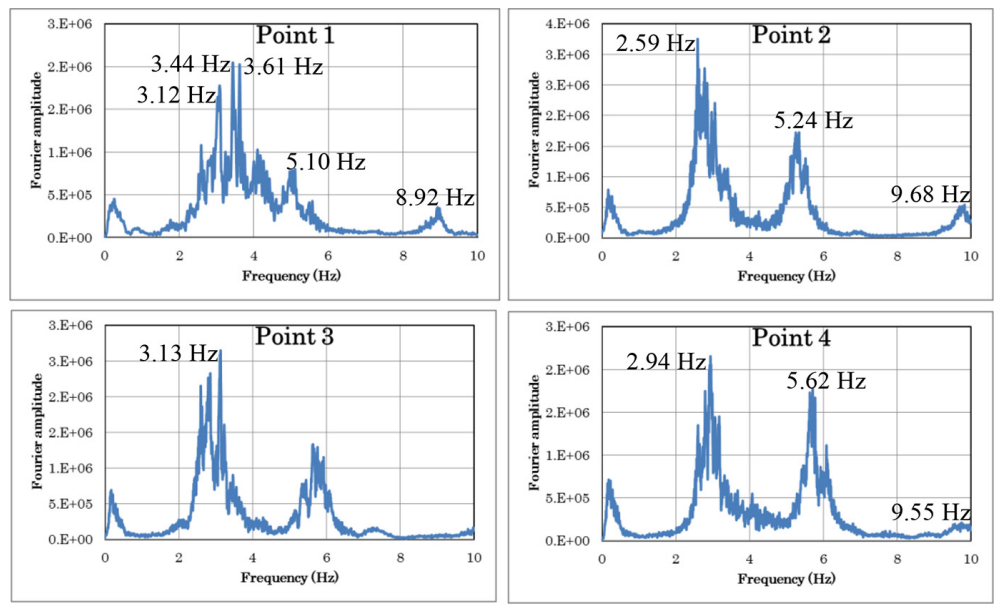

Figure 5: Fourier spectrum responses for different spans of the target bridge.

Fourier analysis was performed using a software called Pwave32 (Version 8.7.12) provided by Tokyo Sokushin Co. Ltd.

Responses show that natural frequency for span (2) presents the lowest value of frequency at $2.59 \mathrm{~Hz}$, since beams have variable depth to permit a smooth transition between span (1) (smaller depth) and span (3) (larger depth), resulting in lower vertical stiffness and therefore lower frequency. It was expected that Spans (1) and (4) could have the same predominant frequency; however, different frequencies were obtained probably due to different support conditions. Span (1) has shorter length and it is reasonable that its predominant frequency is 
different and three peaks are observed in this case (3.12, 3.44 and $3.61 \mathrm{~Hz}$ ). However, 3.44 $\mathrm{Hz}$ can be considered as predominant frequency. Span (1) was selected for measurements using new piezoelectric bolt sensor. This span presents also peaks at 5.10 and $8.92 \mathrm{~Hz}$, and in the next section detailed analysis is presented to explain and verify the characteristics of vibration of this span and vibration of whole bridge.

\section{FINITE ELEMENT MODELING AND MODES OF VIBRATION}

A three-dimensional finite element model of the bridge was created using the commercially available SAP2000 computer program. Figure 6 shows the general model of the target bridge indicating types of spans in relation with points of ambient vibration measurements. Span C is the shortest span with $30.5 \mathrm{~m}$ of length, while spans B and A have $38 \mathrm{~m}$ of length. Span A has large girder depth of $1400 \mathrm{~mm}$ in average. Span C has girder depth of $1100 \mathrm{~mm}$ in average. Span B has girders of variable depth since they are transition from span C of $1100 \mathrm{~mm}$ of girder depth to span A of $1400 \mathrm{~mm}$ of girder depth. The bridge consists of seven spans; however, only representative typical spans (A, B, C) were modeled since each span is separated by an expansion joint and therefore each span can be analyzed as single supported bridge. Then the three types of span models that were considered for analysis of vibration characteristics of the target bridge are shown in Fig. 7.

For each span, supports were modeled using solid elements, and girders of variable cross-section were considered according to bridge design draws. Concrete slab that includes the asphalt carpet were considered for the deck and basically contributes to the mass of structure. It is considered that changes in vertical vibration properties are influenced mainly by stiffness from girders and with a small contribution of the concrete slab.

Modes of vibration for span A are shown in Fig. 8. The first mode of vibration corresponds to the simplest vertical vibration with a predominant frequency of $3.07 \mathrm{~Hz}$. The second mode corresponds to lateral vibration of supports in this case in the longitudinal direction of the bridge, with $3.61 \mathrm{~Hz}$ of predominant frequency. The third mode is transversal vertical vibration with $5.39 \mathrm{~Hz}$ as the predominant frequency. The fourth mode

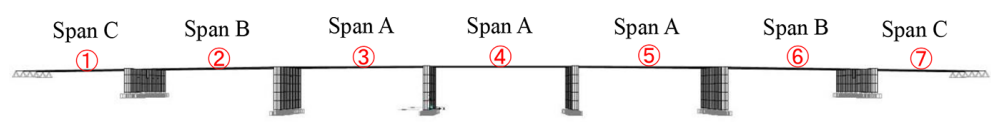

Figure 6: Bridge model with types of span and vibration measurement points.
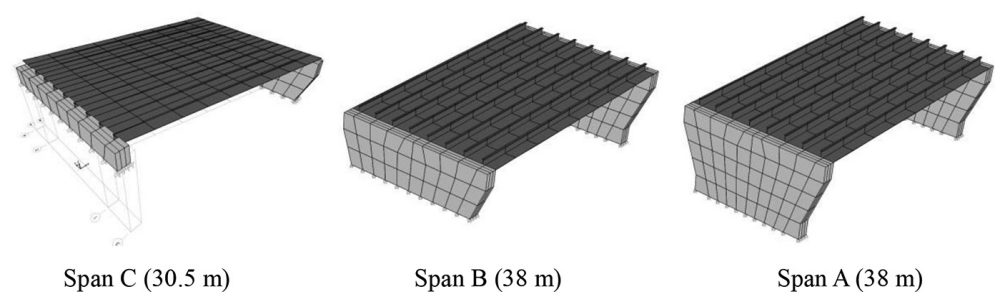

Figure 7: Modeling of typical spans for the target bridge. 

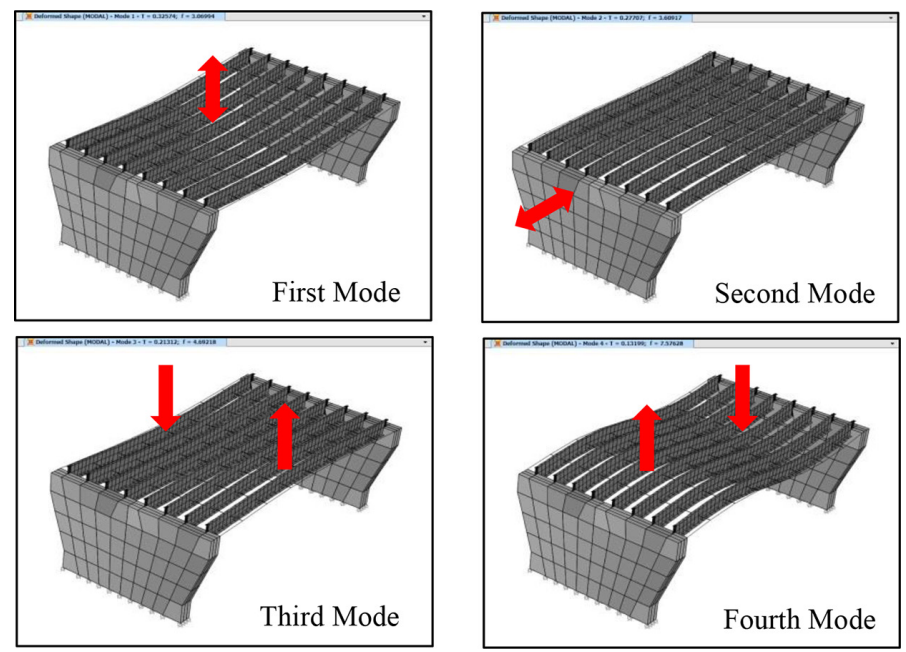

Figure 8: Modes of vibration for span A.

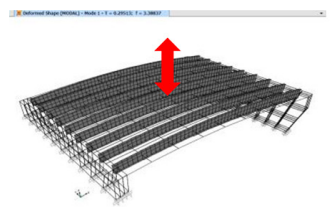

First mode

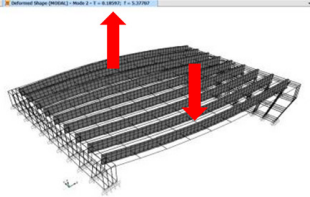

Second mode

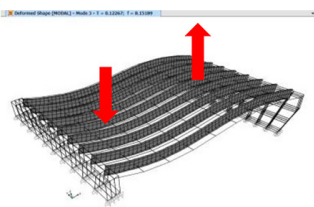

Third mode

Figure 9: Modes of vibration for span C.

corresponds to the second longitudinal mode of vibration with $7.58 \mathrm{~Hz}$ as the predominant frequency. From measurements at point (4), vertical modes (first, third and fourth modes of analysis) were detected as peaks at 2.94, 5.62 and $9.55 \mathrm{~Hz}$, respectively. For span B, similar modes were obtained with frequencies of $2.89,3.57,4.59$ and $6.86, \mathrm{~Hz}$ respectively.

Modes of vibration for the shortest span $\mathrm{C}$ are shown in Fig. 9. The first mode of vibration corresponds to the simplest vertical vibration with a predominant frequency of $3.39 \mathrm{~Hz}$. The second mode is transversal vertical vibration with $5.39 \mathrm{~Hz}$ as the predominant frequency. The third mode corresponds to the second longitudinal mode of vibration with $8.15 \mathrm{~Hz}$ as the predominant frequency. These modes of vibration were also detected during measurements at point (1) as peak at 3.44, 5.10 and $8.92 \mathrm{~Hz}$, respectively.

Measurements and analysis results are summarized in Table 1. In general, good agreement is observed and from analytical results it was possible to identify the modes of vibration that appears as predominant peaks in the Fourier spectrum curves obtained from measurements. For spans A and B, the second mode corresponds to lateral vibration of supports and therefore it is not includes in Table 1 since this table only takes into account vertical modes of vibration. 
Table 1: Comparison of predominant frequencies from analysis and measurements.

\begin{tabular}{lccc}
\hline Span & Mode & Analysis $(\mathrm{Hz})$ & Measurement $(\mathrm{HZ})$ \\
\hline \multirow{3}{*}{ Span A } & 1st & 3.07 & 2.94 \\
& 3rd & 4.69 & 5.62 \\
& 4th & 7.58 & 9.55 \\
Span B & 1st & 2.89 & 2.59 \\
& 3rd & 4.59 & 5.24 \\
& 4th & 6.86 & 9.68 \\
Span C & 1st & 3.39 & 3.44 \\
& 2nd & 5.38 & 5.10 \\
\hline
\end{tabular}

\section{MEASUREMENTS USING PIEZOELECTRIC BOLT SENSOR}

\subsection{Measurement plan}

Piezoelectric bolt sensor was set up at span C near left abutment of the bridge. This span corresponds to point (1) for ambient vibration measurements. For a detailed measurement of span C using piezoelectric sensor, seven points were selected as shown in Fig. 10. For comparison, accelerometers were also set up at same points of measurements. In addition, at middle of span a laser displacement transducer was set up near point 7.

Figure 11 shows some details of sensors setup. Basically, relative displacements between girders and support structure were measured at each point. For this purpose, sensors were fixed firmly to girder flange with its end in contact with support surface. Sensors 1-6 were setup in this way as can be observed in Figs 11a and b. Figure 11c shows the details of accelerometer and sensor setup at point 7 , which is the centre of span. Figure 11d shows the wireless transmission unit (radio unit) and corresponding battery. This unit receives signal from sensor and sent it to the computer for data acquisition. Figure 11e shows the setup of laser displacement transducer. Also, vibration due to moving loads was measured and in Fig. 11f, the truck of $19 \mathrm{t}$ that was used for this test is shown.

\subsection{Characteristics of proposed piezoelectric sensor}

Basic scheme of measurement systems are shown in Fig. 12. Fig. 12a shows the proposed system where signals from piezoelectric bolt sensors are transmitted to computer by means of a wireless module, which contains a microcomputer board. As can be observed, the proposed system is simple and it is easy to install in situ. Former measurement systems require more equipment such as energy generator, signal amplifiers, etc., as can be observed in Fig. $12 \mathrm{~b}$ for the case of measurements using accelerometers.

The piezoelectric bolt sensor is shown in Fig. 13a. Basically, it consists of a piezoelectric cable located in its inner core and external cover of urethane resin resulting in a nominal diameter of $15 \mathrm{~mm}$. The structure of piezoelectric cable is shown in Fig. 13b. The piezoelec- 

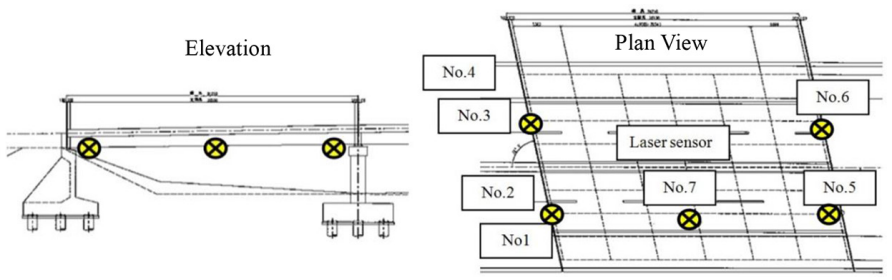

Figure 10: General setup of points of measurements.

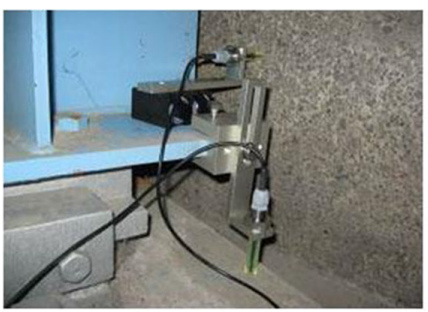

(a)

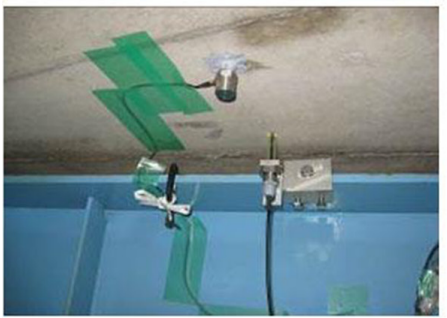

(c)

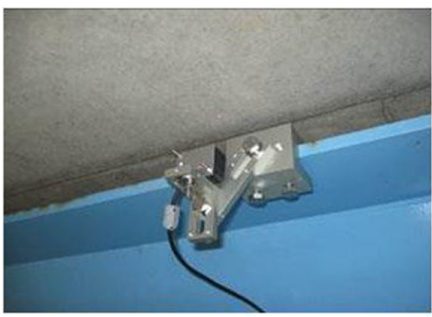

(e)

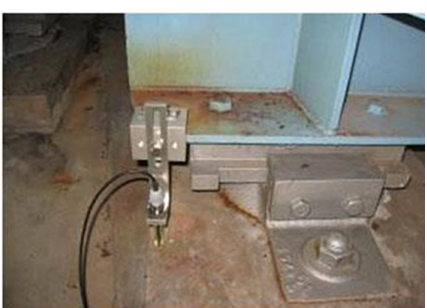

(b)

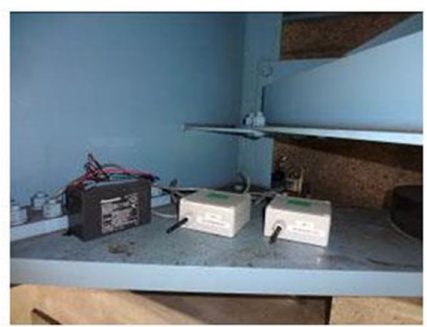

(d)

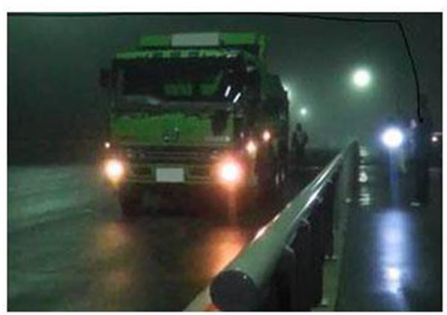

(f)

Figure 11: Details of sensor setup and measurements. (a) Sensor nos 1, 3, and 2, 4, (b) sensor nos 5 and 6, (c) sensor no. 7 and accelerometer, (d) radio unit, (e) laser sensor, and (f) the 19 theavy duty truck.

tric film that acts as electric condensor emits voltage when the cable is subjected to an external action that produces deformation on the cable, especially in the case of dynamic action or vibration.

As is shown in Fig. 14a, the sensor is connected to a radio unit, which sends a wireless signal to a controller connected to a computer. The sensor itself does not need input energy to emit its response; however, radio unit requires a source of energy. Signals from sensor can 


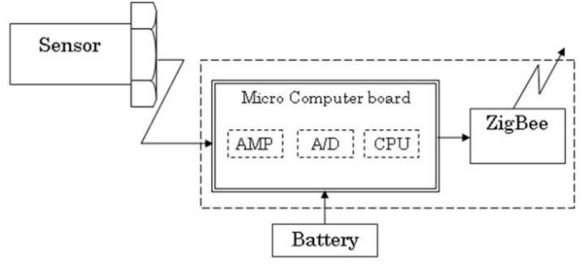

(a)

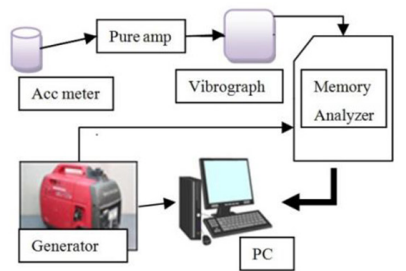

(b)

Figure 12: Scheme of measurement systems. (a) Proposed system and (b) former systems.

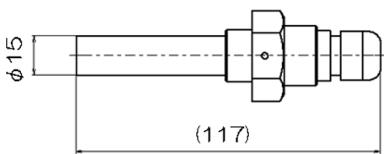

(a)

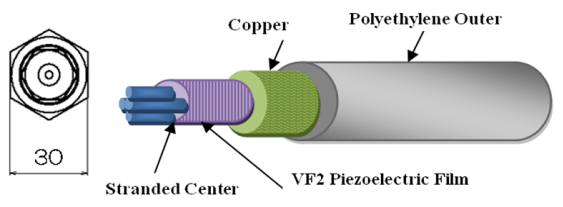

(b)

Figure 13: Proposed piezoelectric bolt sensor. (a) Bolt sensor and (b) details of piezoelectric cable.

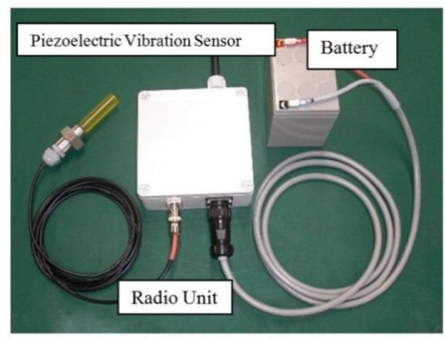

(a)

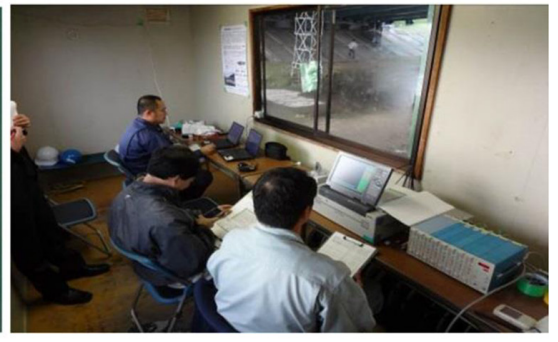

(b)

Figure 14: Sensor signal transmission and general layout of control room. (a) Sensor unit and (b) control room.

be monitored from a control room as shown in Fig. 14b. In this research, a prefabricated portable room was installed near target bridge to perform measurements.

Figure 15a shows the general layout of a vibration test of bolt sensor using a small vibration machine that were carried out to verify sensor response to dynamic actions. These tests were performed at fixed amplitudes and therefore it is supposed that the sensors behave under a fixed harmonic force. For comparison, displacement of the vibration machine was measured by means of a laser displacement transducer. Vibration test was performed for $0.05,0.1$ and $0.2 \mathrm{~mm}$ of amplitude, respectively. For each amplitude value, the frequency was set up from 2 to $20 \mathrm{~Hz}$. The curves that relate the frequency, amplitude and the maximum output voltage of the sensor are shown in Fig. 15b. 


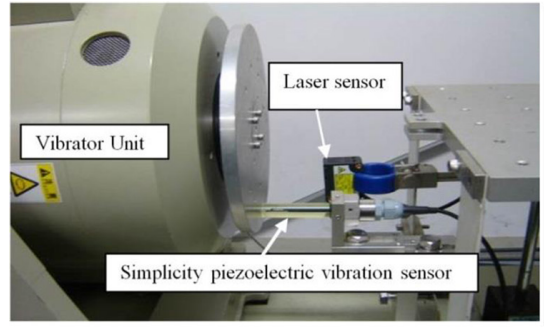

(a)

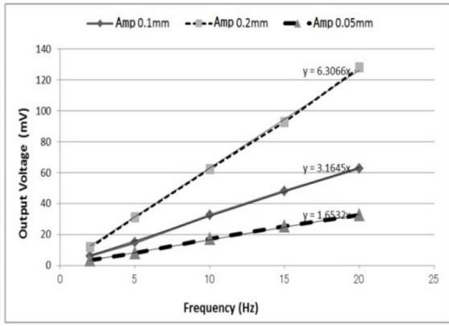

(b)

Figure 15: Vibration test using piezoelectric bolt sensors. (a) Vibration test setup and (b) frequency and output voltage relationship.

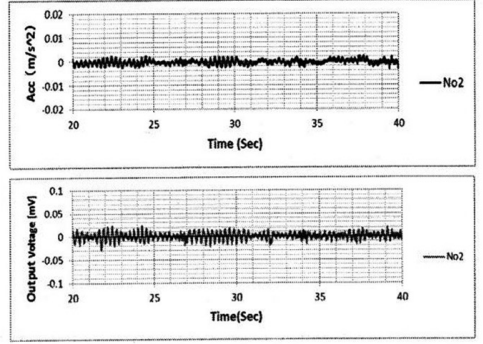

(a) Recorded signals at Point No 2
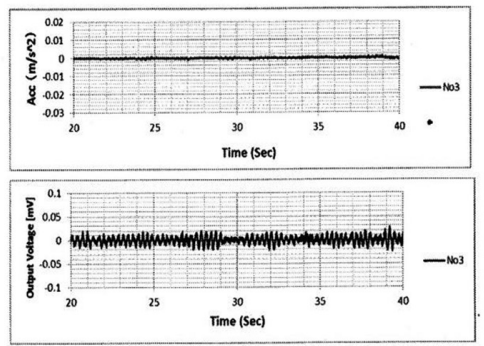

(c) Recorded signals at Point No 3
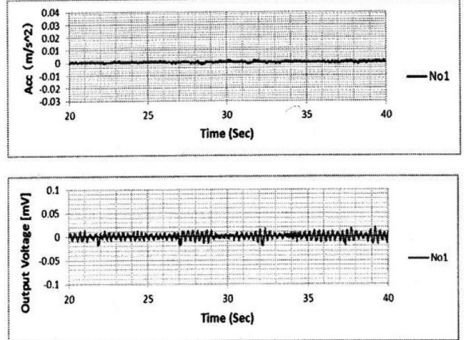

(b) Recorded signals at Point No 1

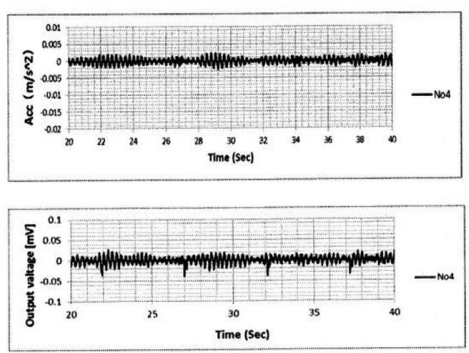

(d) Recorded signals at Point No 4

Figure 16: Measurement signals from accelerometers and from bolt sensors. Recorded signals at point nos. (a) 2, (b) 1, (c) 3 and (d) 4 .

\subsection{Estimation of predominant frequency using piezoelectric sensors}

As illustrative examples of measurement results, responses at measurement points 1-4 are shown in Fig. 16. Upperwave that is shown for each point corresponds to acceleration obtained by means of accelerometers $\left(\mathrm{m} / \mathrm{s}^{2}\right)$. Bottom wave for each point represents the voltage output from the piezoelectric bolt sensors $(\mathrm{mV})$.

From recorded signals, predominant frequencies were obtained by Fourier analysis. In Fig. 17, Fourier spectrum for signals from point nos. 1 to 6 is shown. Upper part of each figure corresponds to accelerometer results and bottom part corresponds to proposed sen- 


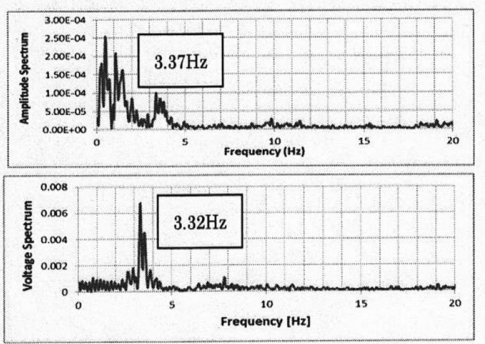

Point No 1
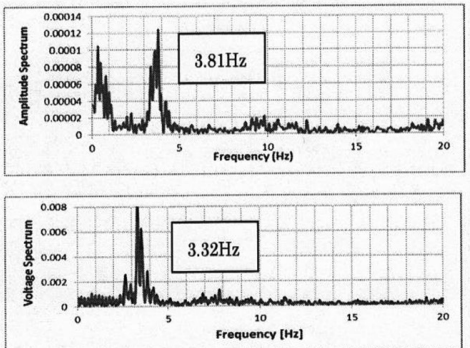

Point No 3
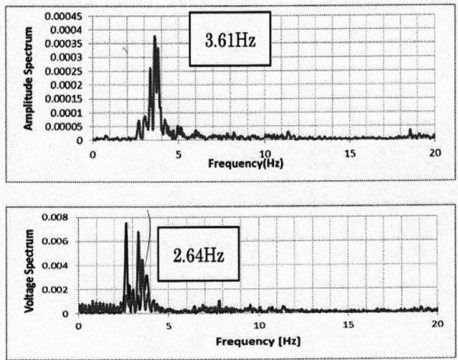

Point No 5

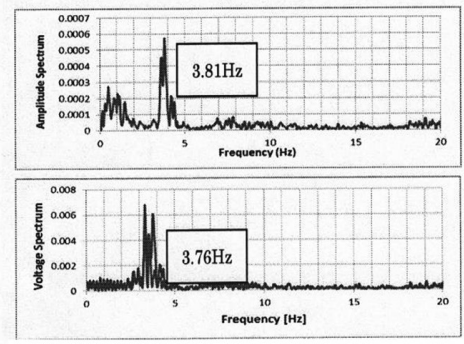

Point No 2
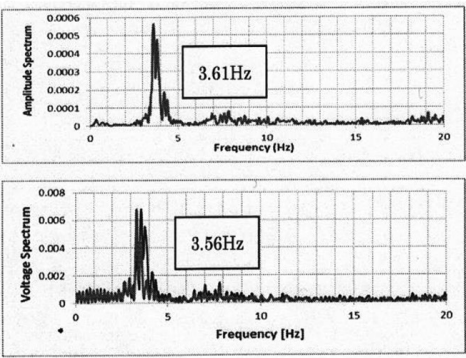

Point No 4
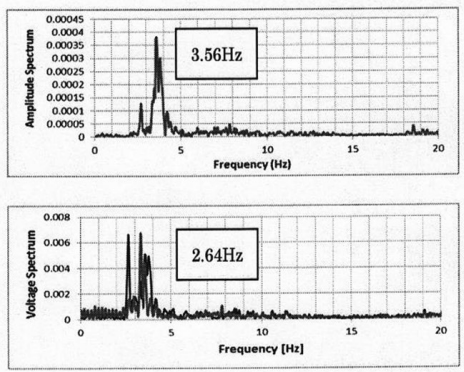

Point No 6

Figure 17: Predominant frequencies from Fourier analysis.

sor results. Results for point nos. 1, 2 and 4 show good agreement between accelerometer results and proposed sensor results. The difference of results at point nos. 5 and 6 is believed due to that proposed sensors and accelerometers are not set up at same location. However, in the Fourier spectrum for proposed sensor a second peak near $3.6 \mathrm{~Hz}$ is observed, which is comparable with the predominant frequencies obtained from accelerometers.

Figure 18 shows a comparison of proposed sensor response and laser displacement transducer response when the truck of $19 \mathrm{t}$ runs on a target span at a velocity of $20 \mathrm{~km} / \mathrm{h}$. Although this measurement corresponds to relative displacement between girder and slab and therefore only small displacement can be detected, external action (in this case, load from truck) was clearly captured by both sensors as can be observed in the disturbance at the central part of the figure. 


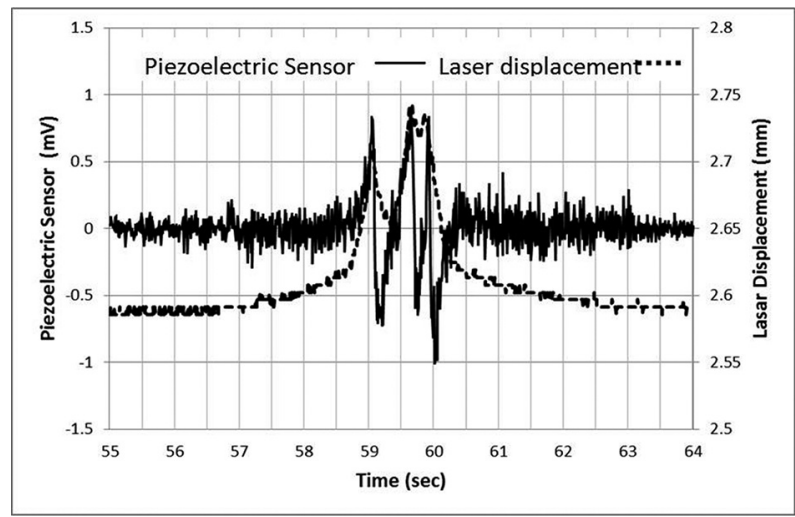

Figure 18: Comparison of sensor response and laser transducer response.

\section{CONCLUSIONS}

In this research, a new smart simple piezoelectric sensor and its corresponding data acquisition system were developed to be used for real-time structural health monitoring of structures. Installation of the system in the selected portion of a target bridge has permitted to perform the monitoring of the structural response for free vibration and vibration in case of moving loads (vehicle loads). The applicability of this new bolt-type sensor for structural health monitoring and estimation of dynamic characteristics of a bridge structure was verified. Simultaneously, commercial accelerometers were used for vibration measurements to compare with those measurements using proposed system. In general, predominant frequencies obtained from in situ measurements using accelerometers and proposed bolt sensors show good agreement.

It was also verified that the proposed sensor could be used also to detect impact loads acting on bridge structures. In this case, verification was done by performing measurements using moving loads from a truck of 19 t. Measurement results from laser displacement transducer and proposed sensor are comparable.

Results obtained from proposed sensor were compared with results obtained from ambient vibration measurements. In addition, finite element model was constructed to verify analytically vibration characteristics of target structures. The approach based on ambient vibration measurements and finite element modeling has permitted to identify modal characteristics of target structure. In this paper, the identification of first three modes related to the vertical vibration of the bridge and their predominant frequencies of vibration was possible by comparison of ambient vibration measurements results with analytical results. Measured modes of vibration agree well with those obtained analytically. In general, good agreement was found between all results. Therefore, applicability of proposed sensor was verified using other methods of measurements and also by means of finite element method of analysis.

\section{ACKNOWLEDGMENT}

The authors acknowledge the Japan Society for the Promotion of Science for a Grant-in-Aid for Scientific Research on Smart Structure Sensing System Using Piezoelectric Cable, under which this research was conducted. 


\section{REFERENCES}

[1] Ministry of Land, Infrastructure and Transport, Report on 'Research on upgrading of soundness evaluation method for highway PC bridges', Technical Notes of the National Institute for Land and Infrastructure Management, No. 623, 2010, pp. 6-14 (in Japanese).

[2] Shimbun, A., "The Ministry of Land, Infrastructure and Transport announced that 121 bridges are in risk of collapse", newspaper article, Asahi Newspaper, November 4, 2009 (in Japanese).

[3] Kurosaki, S., Sasaki, Y. \& Izumi, S., Trial of measurements for axial force of bolt using piezo cable. Journal of the Japanese Society for Non-Destructive Inspection, 56(3), pp. 149-154, 2007 (in Japanese).

[4] Nitta, Y., Imamoto, K. \& Nishitani, A., Structural health monitoring using piezoelectric cable, Summaries of Technical Papers of Annual Meeting Architectural Institute of Japan, B-2, Structures II, Structural Dynamics Nuclear Power Plants, 2006, pp. 891-892 (in Japanese).

[5] Tokyo Sensor Co., Ltd, P "Product Information: Piezoelectric cable, Traffic Sensors", Product catalog 2010, pp. 16-17 (in Japanese).

[6] Tokyo Sensor Co., Ltd, "Piezo Film Technical Manual", user manual, V1.0, R1, 2001, pp. 17-18 (in Japanese).

[7] Chang, F.-K., The demands and challenges. Proceedings of the 3rd International Workshop on Structural Health Monitoring, Stanford University: Stanford, CA, pp. 1-8, 2001.

[8] Nakamura, M. \& Yasui, Y., Damage evaluation of a steel structure subjected to strong earthquake motion based on ambient vibration measurements, Journal of Structural and Construction Engineering - Transactions of AIJ, 517, pp. 61-68, 1999 (in Japanese).

[9] Okabayashi, T., Okumatsu, T. \& Nakamiya, Y., Experimental study of structural damage detection using the high accurate structural vibration-estimation system. Journal of Structural Engineering A, 51A, pp. 479-490, 2005 (in Japanese).

[10] Shimoi, N., Cuadra, C. H., Madokoro, H. \& Saijo, M., Simple smart piezoelectric bolt sensor for structural monitoring of bridges. International Journal of Instrumentation Science, 1(5), pp.78-83, 2012. http://dx.doi.org/10.5923/j.instrument.20120105.03

[11] Nakamura, M., Development of structural health monitoring system, Measurement and Control, 41(11), pp. 819-824, 2002 (in Japanese). 